\title{
Effect of Dietary Maitake (Grifola frondosa) Mushrooms on Plasma Cholesterol and Hepatic Gene Expression in Cholesterol-Fed Mice
}

\author{
Mayumi Sato ${ }^{1 *}$, Yoshihiko Tokuji ${ }^{2}$, Shozo Yoneyama1, Kyoko Fujii-Akiyama ${ }^{2 \S}$, \\ Mikio Kinoshita ${ }^{2}$, Hideyuki Chiji ${ }^{3}$ and Masao Ohnishi ${ }^{2 \dagger}$ \\ ${ }_{1}^{1}$ Forest Products Research Institute, Hokkaido Research Organization (Nishikagura 1-10, Asahikawa, Hokkaido 071-0198, Japan) \\ ${ }^{2}$ Department of Food Science, Obihiro University of Agriculture and Veterinary Medicine (Inada-cho, Obihiro, Hokkaido 080-8555, Japan) \\ ${ }^{3}$ Department of Food Science and Human Nutrition, Faculty of Human Life Sciences, Fuji Women's University, (Hanakawa Minami 4-5, Ishikari, \\ Hokkaido 061-3204, Japan) \\ $\S$ Present address: Tokyo Metropolitan Industrial Technology Research Institute (Aomi 2-4-10, kotoku, Tokyo 135-0064, Japan) \\ ${ }^{\dagger}$ Present address: Department of Food Science and Human Nutrition, Faculty of Human Life Sciences, Fuji Women's University, (Hanakawa \\ Minami 4-5, Ishikari, Hokkaido 061-3204, Japan)
}

\begin{abstract}
To investigate the effects of dietary Grifola frondosa on cholesterol, normal mice were fed a diet containing $1 \%$ cholesterol (HC group) or $1 \%$ cholesterol and $10 \%$ freeze-dried $G$. frondosa powder (HC+G group) for 4 weeks and hepatic and plasma lipid levels were compared with those of a cholesterol-free dietfed mice ( $\mathrm{N}$ group). Hepatic total cholesterol (TC), triacylglycerol contents were considerably increased and plasma TC / phospholipid (PL) was also increased significantly in the HC group compared with the $\mathrm{N}$ group. However, plasma TC content decreased in the $\mathrm{HC}+\mathrm{G}$ group compared with the $\mathrm{HC}$ group. To characterize the mechanisms responsible for lowered plasma cholesterol in G. frondosa-supplemented mice, hepatic gene expression was profiled using DNA microarray and gene ontology. Genome analyses revealed that de novo cholesterol synthesis genes were suppressed following cholesterol intake. However, expression of bile acid biosynthesis and low-density lipoprotein receptor genes showed little change. Scarb1, Abcg5, and $A b c g 8$, involved in cholesterol transport and excretion, were slightly upregulated in the $\mathrm{HC}+\mathrm{G}$ group compared with the HC group. These data indicate the plasma cholesterol-lowering effect of $G$. frondosa. Moreover, fatty acid (FA) $\beta$-oxidation was promoted via adipocytokine signaling pathways, and $\mathrm{Saa}$, encodes serum amyloid A related to arteriosclerosis, was suppressed in the $\mathrm{HC}+\mathrm{G}$ group.
\end{abstract}

Key words: DNA microarray, cholesterol, Grifola frondosa, mushroom, functional properties

\section{INTRODUCTION}

Ischemic heart disease and stroke and other forms of cerebrovascular disease are leading causes of death global$\mathrm{ly}^{11}$. Hypercholesterolemia, an important risk factor for these diseases, is closely related to dietary habits. Therefore, functionality of foods attracts attention for the prevention and improvement of symptoms. Mushrooms have long been considered to have beneficial physiological effects. Their cholesterol-lowering ${ }^{2-4)}$ and antiatherogen$i c^{5)}$ effects are known. The hypocholesterolemic compound, eritadenine is isolated from Lentinus edodes and to a lesser extent in Agaricus bisporus ${ }^{6-9)}$.

We previously evaluated functionality of foods using comprehensive analyses of genomes ${ }^{10-12)}$ and demonstrat- ed the utility of DNA microarrays for elucidating metabolic and signaling mechanisms of such dietary supplements in vivo. Recently, we analyzed hepatic gene expression following mushroom intake and demonstrated upregulation of various genes involved in lipid metabolism and the immune system $^{10)}$. Grifola frondosa (Maitake), which is commonly consumed in Japan, has been recognized for its cholesterol-lowering effects ${ }^{2-5)}$. However, with the exception of the low density lipoprotein(LDL) receptor ${ }^{2}$, few genomic mechanisms have been reported.

To evaluate the effects of dietary $G$. frondosa on cholesterol intake, hepatic gene expression profiles were analyzed in the normal mice fed a $1 \%$ cholesterol-containing diet and mice fed 1\% cholesterol and 10\% freeze-dried $G$.

\footnotetext{
*Correspondence to: Mayumi Sato, Hokkaido Research Organization Forest Products Research Institute, Nishikagura 1-10, Asahikawa, Hokkaido 071-0198, Japan

E-mail: sato-mayumi@hro.or.jp

Accepted August 19, 2013 (received for review May 11, 2013)

Journal of Oleo Science ISSN 1345-8957 print / ISSN 1347-3352 online

http://www.jstage.jst.go.jp/browse/jos/ http://mc.manusriptcentral.com/jjocs
} 
frondosa powder using DNA microarrays. In addition, the mechanism by which $G$. frondosa improves lipid metabolism was examined.

\section{MATERIALS AND METHODS}

\subsection{Experimental samples}

G. frondosa (strain: Gf433) were cultured according to Yoneyama et $a l .{ }^{13)}$. Harvested fruit bodies were autoclaved at $100^{\circ} \mathrm{C}$ for $10 \mathrm{~min}$, freeze-dried, and powdered.

\subsection{Animals and diets}

The experimental diet was prepared according to the AIN-76 formulation. Dietary fiber content in mushrooms was calculated according to food composition data ${ }^{14)}$. Cellulose powder in the control diet was substituted with mushroom powder in the experimental diet, and the sucrose content was modified (Table 1).

Four-week-old male ICR mice (CLEA Japan Inc., Tokyo) were fed AIN-76 pellets for 1 week of adaptation. The mice were then randomly divided into three groups of five each and fed the normal diet (N group; AIN-76 pellets) or experimental diets containing 1\% cholesterol (HC group) or 1\% cholesterol and $G$. frondosa powder ( $\mathrm{HC}+\mathrm{G}$ group) for 4 weeks (Table 1). The mice were kept in an air-conditioned room at $23 \pm 2^{\circ} \mathrm{C}$ with $40 \pm 10 \%$ relative humidity, a 12 -h light/dark cycle was followed, and free access to food and water was allowed. The mice were fasted for $16 \mathrm{~h}$ before being anesthetized with diethyl ether. Blood was immediately collected from hearts. Livers were isolated and stored at $-80^{\circ} \mathrm{C}$ in RNAlater ${ }^{\circledR}$ (Ambion, Austin, TX, USA) until

Table 1 Composition of the diets (\%).

\begin{tabular}{lrrr}
\hline \multirow{2}{*}{ Component } & \multicolumn{3}{c}{ Dietary group } \\
\cline { 2 - 4 } Sucrose & $\mathrm{N}$ & $\mathrm{HC}$ & $\mathrm{HC}+\mathrm{G}$ \\
\hline Casein & 50.0 & 49.5 & 46.7 \\
Corn starch & 20.0 & 19.8 & 18.7 \\
Corn oil & 15.0 & 14.9 & 14.0 \\
Cellulose & 5.0 & 5.0 & 4.7 \\
AIN-76 mineral mixture & 3.5 & 3.5 & 3.3 \\
AIN-76 vitamin mixture & 1.0 & 1.0 & 0.9 \\
DL-methionine & 0.3 & 0.3 & 0.3 \\
Choline bitartrate & 0.2 & 0.2 & 0.2 \\
Cholesterol & 0.0 & 1.0 & 0.9 \\
Mushroom powder & 0.0 & 0.0 & 10.3 \\
\hline Total & 100.0 & 100.0 & 100.0 \\
\hline
\end{tabular}

$\mathrm{N}$, normal diet group; $\mathrm{HC}$, high cholesterol group; $\mathrm{H}+\mathrm{G}$, high cholesterol plus G. frondosa powder group
RNA extraction. All mice were treated according to the guidelines for experimental animal use of Obihiro University of Agriculture and Veterinary Medicine, Japan.

\subsection{Analysis of plasma and liver lipids}

Blood was separated into plasma by centrifugation $\left(4^{\circ} \mathrm{C}\right.$, 1500 g, 15 min). Plasma total cholesterol (TC), high-density lipoprotein cholesterol (HDL-C), triglyceride(TG), and phospholipid (PL) concentrations were measured using commercial enzymatic test kits ${ }^{10)}$. LDL cholesterol (LDL-C) was estimated as the difference between TC and HDL-C concentrations. Liver lipids were extracted according to Danno et al. ${ }^{15)}$. TC, TGs, and PLs in the extracts were measured using the kits. Statistical analyses were performed using ANOVA with the Tukey-Kramer HSD test $(p<0.05)$ with JMP 5.0.1 J (SAS Institute, Cary, NC, USA).

\subsection{DNA microarray analysis}

Total RNA was isolated from the livers using an SV total RNA Isolation System (Promega, Madison, WI, USA). Its quality was examined by its absorbance and by electrophoresis. Equal amounts of the RNA from five mice of each experiment group were pooled to normalize individual differences for DNA microarray analysis.

Labeled cRNA was synthesized using $2 \mu \mathrm{g}$ of total RNA as a template with GeneChip ${ }^{\circledR}$ One-Cycle Target Labeling and Control Reagents (Affymetrix, Santa Clara, CA, USA). cRNA was fragmented as per the standard protocol and then hybridized at $45^{\circ} \mathrm{C}$ for $16 \mathrm{~h}$ to GeneChip ${ }^{\circledR}$ Mouse Genome 430A 2.0 Array (Affymetrix). The array was washed and stained with GeneChip ${ }^{\circledR}$ Fluidics Station 450 and GeneChip ${ }^{\circledR}$ Hybridization, Wash, and Stain Kit (Affymetrix) and then scanned using GeneChip ${ }^{\circledR}$ Scanner 3000 (Affymetrix). The collected fluorescence signals were corrected for background and converted into numeric data using GeneChip $^{\circledR}$ Operating Software (Affymetrix). Gene Spring GX 7.3.1 (Agilent Technologies, Santa Clara, CA, USA) was used to normalize data and compare the expression levels. The probes with the data flag "presence" were extracted. In comparison with the probes for the $\mathrm{N}$ group, the extracted probes whose signal level changed $>1.5$-fold were identified. Functional clustering of differentially expressed genes was assigned according to the Database for Annotation, Visualization and Integrated Discovery (DAVID)v6.7 (http://david.abcc.ncifcrf.gov/) at "medium" stringency based on the Gene Ontology (GO) biological process. These genes were categorized and mapped onto pathways using the Kyoto Encyclopedia of Genes and Genomes (KEGG) pathway database (http://www.kegg.jp/ja/). 


\section{RESULTS AND DISCUSSION}

3.1 Effects of cholesterol and $G$. frondosa intake on liver and plasma lipids in mice

Food consumption of the $\mathrm{HC}+\mathrm{G}$ group was highest in the three groups (Table 2). However, body and epididymal fat weights did not differ significantly between treatment groups throughout the experimental period (Table 2). Hepatic and plasma lipid contents were shown in Table 2 and 3, respectively. Total lipids, TC, and TG contents in livers of the HC group increased considerably compared with those of the $\mathrm{N}$ group (Table 2). TC/PL and LDL-C/PL in plasma significantly increased and TG/PL slightly de- creased in the HC group (Table 3 ). Hepatic TC and TG contents were lower in the $\mathrm{HC}+\mathrm{G}$ group than in the $\mathrm{HC}$ group. In the $\mathrm{HC}+\mathrm{G}$ group, TC/PL in plasma were significantly lower than those in the $\mathrm{HC}$ group but similar to those in the $\mathrm{N}$ group. LDL-C/PL in the $\mathrm{HC}+\mathrm{G}$ group were also lower than those in the $\mathrm{HC}$ group. TG/PL in the $\mathrm{HC}+$ $\mathrm{G}$ group was significantly lower than those in the $\mathrm{N}$ group. It has been reported that the serum TC/PL is significantly increased in the coronary heart disease group in contrast to the normal group ${ }^{16)}$. Our data suggest that ingestion of G. frondosa reduced this ratio.

Table 2 Metabolic parameters of mice fed experimental diets for 4 weeks.

\begin{tabular}{|c|c|c|c|}
\hline & $\mathrm{N}$ & $\mathrm{HC}$ & $\mathrm{HC}+\mathrm{G}$ \\
\hline Initial BW $(\mathrm{g})^{a}$ & $33.9 \pm 2.2^{A}$ & $33.3 \pm 0.6^{A}$ & $33.6 \pm 1.7^{A}$ \\
\hline Final BW $(\mathrm{g})^{b}$ & $39.0 \pm 3.9^{A}$ & $38.6 \pm 1.4^{A}$ & $37.9 \pm 3.1^{A}$ \\
\hline Food consumption ( $\mathrm{g} / 5$ mice per day) & $26.3 \pm 4.5^{B}$ & $23.0 \pm 4.5^{B}$ & $35.9 \pm 3.1^{A}$ \\
\hline Epididymal fat (g) & $1.2 \pm 0.4^{A}$ & $0.8 \pm 0.3^{A}$ & $0.7 \pm 0.2^{A}$ \\
\hline \multicolumn{4}{|l|}{ Liver } \\
\hline Liver weight (g) & $2.0 \pm 0.4^{A}$ & $2.4 \pm 0.6^{A}$ & $1.8 \pm 0.3^{A}$ \\
\hline Total lipid content $(\%)$ & $7.5 \pm 2.3^{B}$ & $18.9 \pm 4.2^{A}$ & $16.8 \pm 6.9^{A}$ \\
\hline Total cholesterol content $(\%)$ & $0.53 \pm 0.15^{B}$ & $3.29 \pm 0.50^{A}$ & $2.53 \pm 1.09^{A}$ \\
\hline Triacylglycerol content $(\%)$ & $4.2 \pm 1.9^{B}$ & $9.0 \pm 1.3^{A}$ & $7.9 \pm 3.7^{A B}$ \\
\hline
\end{tabular}

$\mathrm{N}$, normal diet group; $\mathrm{HC}$, high cholesterol group; $\mathrm{H}+\mathrm{G}$, high cholesterol plus $G$. frondosa powder group

Values are expressed as the mean $\pm \operatorname{SD}(n=5)$.

Values not sharing the same superscript letters (A, B, C) within each family are significantly different, as indicated by the Tukey-Kramer HSD test $(p<0.05)$.

${ }^{a}$ Initial body weight was measured before starting dietary protocols.

${ }^{b}$ Final body weight was measured before sacrifice.

Table 3 Plasma lipid of mice fed experimental diets for 4 weeks.

\begin{tabular}{lrrr}
\hline & \multicolumn{1}{c}{$\mathrm{N}$} & \multicolumn{1}{c}{$\mathrm{HC}$} & \multicolumn{1}{c}{$\mathrm{HC}+\mathrm{G}$} \\
\hline Total cholesterol (mg/dL) & $99.5 \pm 25.0^{A}$ & $134.1 \pm 39.1^{A}$ & $98.2 \pm 27.5^{A}$ \\
Total cholesterol / PL & $0.47 \pm 0.04^{B}$ & $0.63 \pm 0.05^{A}$ & $0.50 \pm 0.05^{B}$ \\
HDL-cholesterol (mg/dL) & $82.9 \pm 16.6^{A}$ & $96.5 \pm 30.8^{A}$ & $76.6 \pm 18.1^{A}$ \\
HDL-cholesterol / PL & $0.40 \pm 0.06^{A}$ & $0.46 \pm 0.04^{A}$ & $0.39 \pm 0.02^{A}$ \\
LDL-cholesterol (mg/dL) & $16.6 \pm 14.7^{A}$ & $37.6 \pm 13.3^{A}$ & $21.6 \pm 11.0^{A}$ \\
LDL-cholesterol / PL & $0.07 \pm 0.06^{B}$ & $0.17 \pm 0.06^{A}$ & $0.11 \pm 0.04^{A B}$ \\
Triglyceride (mg/dL) & $184.0 \pm 77.0^{A}$ & $132.9 \pm 40.5^{A B}$ & $94.5 \pm 23.9^{B}$ \\
Triglyceride / PL & $0.86 \pm 0.27^{A}$ & $0.64 \pm 0.17^{A B}$ & $0.49 \pm 0.12^{B}$ \\
Phospholipids (mg/dL) & $210.1 \pm 45.4^{A}$ & $210.6 \pm 57.0^{A}$ & $194.1 \pm 37.1^{A}$ \\
\hline
\end{tabular}

$\mathrm{N}$, normal diet group; $\mathrm{HC}$, high cholesterol group; $\mathrm{H}+\mathrm{G}$, high cholesterol plus $G$. frondosa powder group

Values are expressed as the mean $\pm \operatorname{SD}(n=5)$.

Values not sharing the same superscript letters (A, B, C) within each family are significantly different, as indicated by the Tukey-Kramer HSD test $(p<0.05)$. 
3.2 Altered expression of hepatic genes following cholesterol and $G$. frondosa supplementation

To characterize the mechanisms leading to differences in liver and plasma cholesterol and TG contents between the experimental diet groups, hepatic gene expression was analyzed using DNA microarray. Table 4 shows significantly altered $(p<0.05) \mathrm{GO}$ terms related to lipid metabolism. In lipid metabolic processes, steroid metabolic processes, and regulation of lipid metabolic processes, no differences were observed between the number of genes with altered ex- pression in the experimental diet groups.

3.3 Effects of $1 \%$ cholesterol intake on the expression of lipid metabolism-related genes

Table 5 shows the expression levels of genes belonging to the GO term involved in cholesterol metabolism (Table 4). The expression levels in the HC group were compared with those in the $\mathrm{N}$ group.

In GO:0042632, cholesterol homeostasis, Abcg5 (ATPbinding cassette, sub-family G, member 5) expression was

Table 4 Functional annotation clustering of differentially expressed genes.

\begin{tabular}{|c|c|c|c|c|c|}
\hline \multirow{2}{*}{ GO number } & \multirow{2}{*}{ GO term (biological process) } & \multicolumn{2}{|c|}{$\mathrm{HC}$} & \multicolumn{2}{|c|}{$\mathbf{H C}+\mathbf{G}$} \\
\hline & & No. ${ }^{a}$ & $P$ value & No. ${ }^{a}$ & $P$ value \\
\hline GO:0055088 & Lipid homeostasis & 12 & $1.01 \mathrm{E}-03$ & & \\
\hline GO:0055092 & ...Sterol homeostasis & 9 & $6.84 \mathrm{E}-03$ & & \\
\hline GO:0042632 & ...Cholesterol homeostasis & 9 & $6.84 \mathrm{E}-03$ & & \\
\hline GO:0006629 & Lipid metabolic process & 104 & $3.54 \mathrm{E}-03$ & 104 & $2.04 \mathrm{E}-02$ \\
\hline GO:0044255 & Cellular lipid metabolic process & 74 & $7.52 \mathrm{E}-03$ & & \\
\hline GO:0008610 & Lipid biosynthetic process & 46 & $1.59 \mathrm{E}-02$ & 47 & $2.86 \mathrm{E}-02$ \\
\hline GO:0008202 & Steroid metabolic process & 30 & 8.87E-03 & 32 & $6.47 \mathrm{E}-03$ \\
\hline GO:0016125 & Sterol metabolic process & 18 & $5.56 \mathrm{E}-03$ & 17 & $2.21 \mathrm{E}-02$ \\
\hline GO:0008203 & ...Cholesterol metabolic process & 16 & $1.17 \mathrm{E}-02$ & 17 & $9.07 \mathrm{E}-03$ \\
\hline GO:0006695 & ...Cholesterol biosynthetic process & 8 & $1.20 \mathrm{E}-02$ & & \\
\hline GO:0006694 & ...Steroid biosynthetic process & 16 & $1.33 \mathrm{E}-02$ & & \\
\hline GO:0016126 & ..Sterol biosynthetic process & 10 & $5.06 \mathrm{E}-03$ & & \\
\hline GO:0032787 & "'Monocarboxylic acid metabolic process & 46 & 5.39E-03 & & \\
\hline GO:0044255 & ... Cellular lipid metabolic process & 74 & $7.52 \mathrm{E}-03$ & & \\
\hline GO:0019216 & Regulation of lipid metabolic process & 13 & $2.94 \mathrm{E}-02$ & 15 & $8.69 \mathrm{E}-03$ \\
\hline GO:0046890 & Regulation of lipid biosynthetic process & 8 & $9.21 \mathrm{E}-03$ & 8 & $1.29 \mathrm{E}-02$ \\
\hline GO:0042304 & Regulation of fatty acid biosynthetic process & 5 & $1.35 \mathrm{E}-02$ & 5 & $1.68 \mathrm{E}-02$ \\
\hline GO:0045834 & Positive regulation of lipid metabolic process & 7 & 4.92E-02 & & \\
\hline GO:0019218 & Regulation of steroid metabolic process & & & 7 & $4.36 \mathrm{E}-02$ \\
\hline GO:0006643 & Membrane lipid metabolic process & & & 15 & $2.05 \mathrm{E}-02$ \\
\hline GO:0006665 & S... Sphingolipid metabolic process & 13 & 4.67E-02 & 14 & $3.44 \mathrm{E}-02$ \\
\hline GO:0046519 & Sphingoid metabolic process & 10 & $2.50 \mathrm{E}-02$ & & \\
\hline GO:0045834 & Positive regulation of lipid metabolic process & 7 & 4.92E-02 & & \\
\hline
\end{tabular}

$\mathrm{HC}$, high cholesterol group; $\mathrm{H}+\mathrm{G}$, high cholesterol plus $G$. frondosa powder group

${ }^{a}$ The number of genes altered by cholesterol and G. frondosa intake belonging to each GO category $(p<0.05)$. 
upregulated 1.71-fold compared with that in the $\mathrm{N}$ group. The $A b c g 5$ gene functions after forming a heterodimer with Abcg8, i.e., ABCG5/ABCG8. Abcg8 expression was also slightly upregulated 1.49-fold. The heterodimer ABCG5/ ABCG8 is involved in cholesterol excretion from the liver to the bile ${ }^{17,18)}$. In an agreement with the present data, Berge et al. reported that Abcg5 and Abcg8 were expressed at highest levels in the human liver and were upregulated in the livers of the mice fed $2 \%$ cholesterol $^{19)}$. Dietary cholesterol increases oxycholesterol in the body

Table 5 Change (vs N group) in expression of hepatic genes involved in cholesterol homeostasis, cholesterol metabolic process, and regulation of lipid metabolic process.

\begin{tabular}{|c|c|c|c|c|c|}
\hline \multirow{2}{*}{$\begin{array}{l}\text { GenBank } \\
\text { accession }\end{array}$} & \multirow{2}{*}{$\begin{array}{c}\text { Gene } \\
\text { symbol }\end{array}$} & \multirow{2}{*}{ Gene name } & \multirow{2}{*}{$\begin{array}{c}\mathrm{HC} \\
\text { vs N }\end{array}$} & \multicolumn{2}{|c|}{$\mathrm{HC}+\mathrm{G}$} \\
\hline & & & & vs $\mathrm{N}$ & vs HC \\
\hline \multicolumn{6}{|c|}{ GO:0042632 cholesterol homeostasis } \\
\hline NM_031884 & Abcg5 & ATP-binding cassette, sub-family G (WHITE), member 5 & 1.71 & 1.71 & 1.00 \\
\hline AF324495 & Abcg8 & ATP-binding cassette, sub-family G (WHITE), member 8 & 1.49 & 1.89 & 1.26 \\
\hline AI785548 & Apob & Apolipoprotein B & 0.38 & 0.75 & 1.96 \\
\hline AB029929 & Cavl & Caveolin, caveolae protein 1 & 1.54 & 0.75 & 0.49 \\
\hline NM_009846 & $C d 24 a$ & CD24a antigen & 1.64 & 1.73 & 1.05 \\
\hline ВC002148 & Fabp4 & Fatty acid binding protein 4 , adipocyte & 4.16 & 0.96 & 0.23 \\
\hline NM_008061 & $G 6 p c$ & Glucose-6-phosphatase, catalytic & 0.43 & 0.62 & 1.45 \\
\hline BB769209 & $N p c 1$ & Niemann Pick type $\mathrm{C} 1$ & 1.51 & 1.04 & 0.69 \\
\hline BB654116 & $\operatorname{Pex} 2$ & Peroxin 2 & 1.77 & 1.46 & 0.82 \\
\hline BG069809 & & Transcribed locus & 0.64 & 0.88 & 1.38 \\
\hline \multicolumn{6}{|c|}{ GO:0008203 cholesterol metabolic process } \\
\hline AF125307 & $C \ln 8$ & Ceroid-lipofuscinosis, neuronal 8 & 0.76 & 0.54 & 0.70 \\
\hline AV214220 & $C \ln 8$ & Ceroid-lipofuscinosis, neuronal 8 & 0.75 & 0.62 & 0.83 \\
\hline NM_018887 & Cyp39a1 & Cytochrome P450, family 39 , subfamily a, polypeptide 1 & 0.28 & 0.38 & 1.35 \\
\hline NM_010010 & Cyp46al & Cytochrome P450, family 46 , subfamily a, polypeptide 1 & 0.96 & 0.10 & 0.11 \\
\hline NM_020010 & Cyp51 & Cytochrome P450, family 51 & 0.64 & 0.53 & 0.83 \\
\hline BG295389 & Dhcr 24 & 24-Dehydrocholesterol reductase & 0.39 & 0.10 & 0.27 \\
\hline BG065877 & $H d l b p$ & High density lipoprotein (HDL) binding protein & 2.20 & 1.46 & 0.66 \\
\hline BB705380 & Hmgcs 1 & 3-Hydroxy-3-methylglutaryl-Coenzyme A synthase 1 & 0.63 & 0.60 & 0.95 \\
\hline AK004902 & Hmgcs 2 & 3-Hydroxy-3-methylglutaryl-Coenzyme A synthase 2 & 0.55 & 0.40 & 0.73 \\
\hline NM_010476 & $H s d 17 b 7$ & Hydroxysteroid (17-beta) dehydrogenase 7 & 0.54 & 0.76 & 1.39 \\
\hline ВC004801 & Idil & Isopentenyl-diphosphate delta isomerase & 0.46 & 0.66 & 1.43 \\
\hline AV257512 & Insig2 & Insulin induced gene 2 & 0.56 & 0.97 & 1.72 \\
\hline U42467 & Lepr & Leptin receptor & 1.42 & 1.62 & 1.14 \\
\hline U58862 & Lepr & Leptin receptor & 1.46 & 1.55 & 1.06 \\
\hline NM_010719 & Lipe & Lipase, hormone sensitive & 1.49 & 1.70 & 1.14 \\
\hline NM_011314 & Saal & Serum amyloid A 1 & 2.09 & 1.40 & 0.67 \\
\hline BI412871 & Scap & SREBP cleavage activating protein & 0.75 & 0.59 & 0.79 \\
\hline BB224405 & Scarbl & Scavenger receptor class $\mathrm{B}$, member 1 & 1.16 & 1.53 & 1.32 \\
\hline BG064396 & Soat1 & Sterol O-acyltransferase 1 & 1.30 & 1.71 & 1.32 \\
\hline AI326423 & Srebfl & Sterol regulatory element binding factor 1 & 3.15 & 2.74 & 0.87 \\
\hline ВC014769 & $\operatorname{Tm} 7 s f 2$ & Transmembrane 7 superfamily member 2 & 0.59 & 0.55 & 0.94 \\
\hline BB628702 & Vldlr & Very low density lipoprotein receptor & 0.77 & 1.61 & 2.09 \\
\hline
\end{tabular}

$\mathrm{N}$, normal diet group; $\mathrm{HC}$, high cholesterol group; $\mathrm{H}+\mathrm{G}$, high cholesterol plus $G$. frondosa powder group 
Table 5 Continued.

\begin{tabular}{|c|c|c|c|c|c|}
\hline \multirow{2}{*}{$\begin{array}{l}\text { GenBank } \\
\text { accession }\end{array}$} & \multirow{2}{*}{$\begin{array}{l}\text { Gene } \\
\text { symbol }\end{array}$} & \multirow{2}{*}{ Gene name } & \multirow{2}{*}{$\begin{array}{c}\mathrm{HC} \\
\text { vs N }\end{array}$} & \multicolumn{2}{|c|}{$\mathrm{HC}+\mathrm{G}$} \\
\hline & & & & vs $\mathrm{N}$ & vs $\mathrm{HC}$ \\
\hline \multicolumn{6}{|c|}{ GO:0019216 regulation of lipid metabolic process } \\
\hline BE630294 & Adoral & Adenosine A1 receptor & 1.41 & 1.60 & 1.13 \\
\hline AK018763 & Agt & Angiotensinogen (serpin peptidase inhibitor, clade A, member 8) & 0.61 & 0.66 & 1.09 \\
\hline AK014564 & Angptl4 & Angiopoietin-like 4 & 0.50 & 0.60 & 1.19 \\
\hline NM_020581 & Angptl4 & Angiopoietin-like 4 & 0.57 & 0.37 & 0.64 \\
\hline AI785548 & Apob & Apolipoprotein B & 0.38 & 0.75 & 1.96 \\
\hline ВC003248 & Brcal & Breast cancer 1 & 1.61 & 0.59 & 0.36 \\
\hline АВ029929 & Cavl & Caveolin, caveolae protein 1 & 1.54 & 0.75 & 0.49 \\
\hline BF580781 & Hnf4a & Hepatic nuclear factor 4 , alpha & 0.78 & 0.58 & 0.74 \\
\hline ВC011437 & $I l 1 b$ & Interleukin 1 beta & 1.36 & 1.65 & 1.22 \\
\hline AV257512 & Insig2 & Insulin induced gene 2 & 0.56 & 0.97 & 1.72 \\
\hline BB345784 & $\operatorname{Irs} 1$ & Insulin receptor substrate 1 & 0.55 & 0.72 & 1.30 \\
\hline NM_008173 & $\mathrm{Nr} 3 \mathrm{cl}$ & Nuclear receptor subfamily 3 , group $C$, member 1 & 1.28 & 1.45 & 1.13 \\
\hline BB654116 & Pex2 & Peroxin 2 & 1.77 & 1.46 & 0.82 \\
\hline BC016892 & Ppara & Peroxisome proliferator activated receptor alpha & 0.83 & 0.54 & 0.65 \\
\hline BB087946 & Racl & RAS-related C 3 botulinum substrate 1 & 0.54 & 0.69 & 1.26 \\
\hline BI412871 & Scap & SREBP cleavage activating protein & 0.75 & 0.59 & 0.79 \\
\hline AI326423 & Srebfl & Sterol regulatory element binding factor 1 & 3.15 & 2.74 & 0.87 \\
\hline L36062 & Star & Steroidogenic acute regulatory protein & 20.28 & 15.65 & 0.77 \\
\hline U36502 & Stat $5 a$ & Signal transducer and activator of transcription $5 \mathrm{~A}$ & 1.28 & 1.52 & 1.19 \\
\hline AW490135 & Stubl & STIP1 homology and U-Box containing protein 1 & 1.43 & 1.65 & 1.16 \\
\hline $\mathrm{BC} 027242$ & $\operatorname{Vav} 3$ & Vav 3 oncogene & 2.16 & 2.60 & 1.50 \\
\hline
\end{tabular}

N, normal diet group; $\mathrm{HC}$, high cholesterol group; $\mathrm{H}+\mathrm{G}$, high cholesterol plus G. frondosa powder group

and induces ABCG5/ABCG8 upregulation by activating the liver $\mathrm{X}$ receptor $(\mathrm{LXR})^{20)}$. Thus, it is expected that the system for cholesterol excretion from the liver to the bile is upregulated in the cholesterol-supplemented mice. In contrast, the gene encoding Apolipoprotein $\mathrm{B}(A p o b)$, the primary apolipoprotein responsible for endogenous lipoprotein metabolism in VLDLs, was unexpectedly downregulated 0.38 -fold in the HC group. These results indicate that VLDL excretion from the liver was lowered in these animals. Interestingly, plasma Fabp 4 (adipocyte FA-binding protein 4), was reportedly increased in metabolic syndrome patients ${ }^{21)}$ and upregulated 4.16-fold. TG content in the livers of the HC group was higher than that of the $\mathrm{N}$ group (Table 2), and Fabp 4 expression was positively correlated with liver fat content in humans ${ }^{22)}$. Moreover, Fu et al. showed that Fabp 4 overexpression in human THP-1 monocytic cells accelerates cholesterol and TG accumulation in macrophage foam cells ${ }^{23)}$.

In GO:0008203 cholesterol metabolic process, Hmgcs1, Hmgcs2, Idi1, Cyp51, Tm7sf2, Hsd17b7, and Dhcr24 were downregulated (Fig. 1). Increases in dietary cholesterol are likely to suppress de novo cholesterol synthesis, leading to suppression of these genes. It was expected that dietary cholesterol would promote primary bile acid biosynthesis in the liver as cholesterol catabolism was increased. However, Cyp39a1 and Cyp $46 a 1$ of the 24-hydroxylase pathway were not upregulated. In addition, upregulation of cholesterol 7a-hydroxylase (Cyp7a1), which performs the rate-limiting step of bile acid biosynthesis and is controlled by LXR $\alpha$, was not observed (data not shown). These results show that increased liver cholesterol does not necessarily upregulate genes involved in bile acid biosynthesis.

Srebf1, which encodes sterol regulatory element binding factor 1 (SREBP1), was upregulated 3.15-fold in cholesterol-fed mice (Table 5). Yabe et al. reported that SREBP1c is mainly expressed in liver and adipose tissue and controls genes involved in FA and TG synthesis ${ }^{24)}$. In addition, decrease in Insig2 expression might allow SREBP1c to be processed even when hepatic cholesterol concentrations 


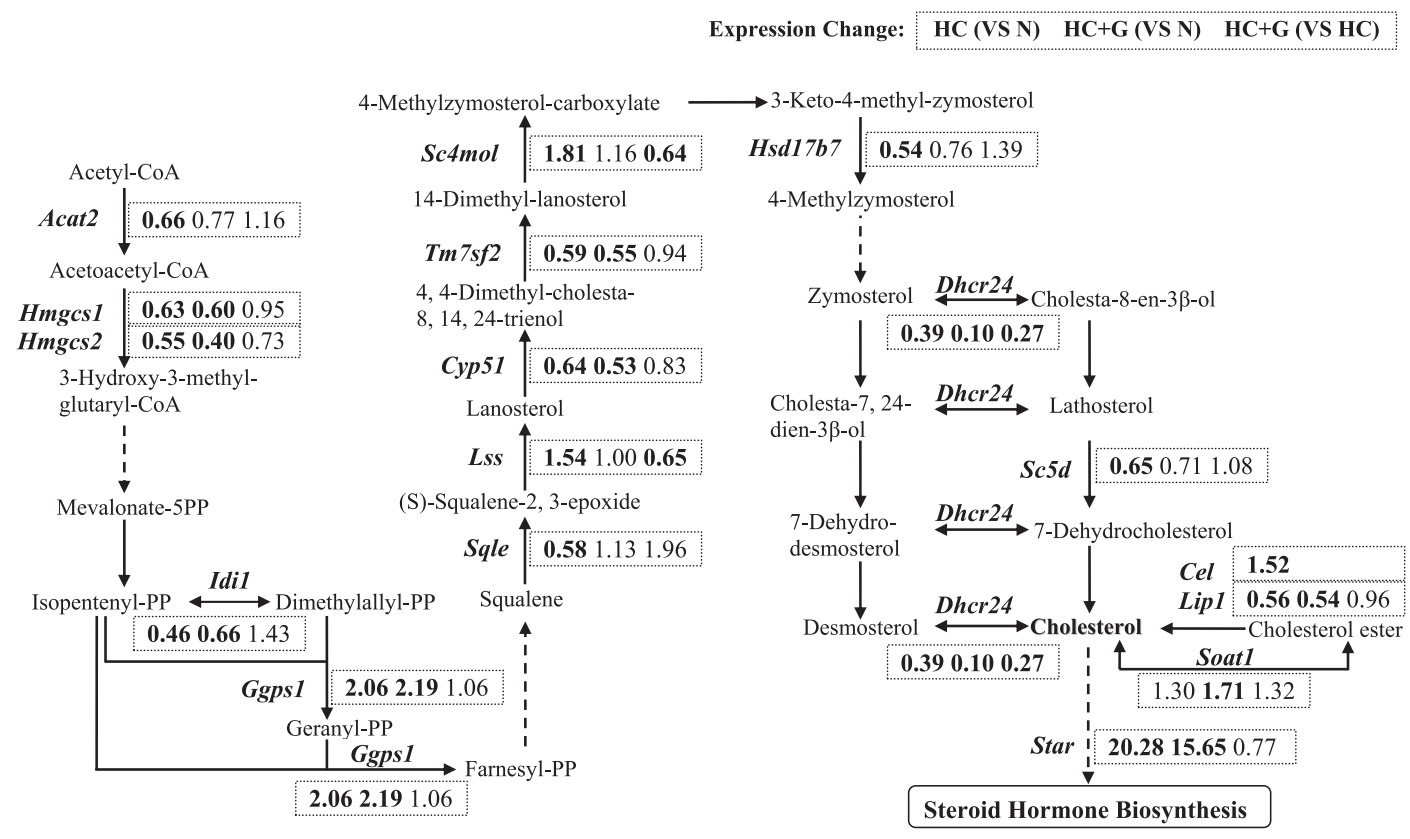

Fig. 1 Expression of Steroid Biosynthesis Genes Induced by Ingestion of Cholesterol and G. frondosa. HC, high cholesterol group; $\mathrm{H}+\mathrm{G}$, high cholesterol plus $G$. frondosa powder group.

are relatively high and FA synthesis is activated. In the present study, FA synthase (Fasn) was not upregulated following cholesterol intake (1.27-fold), but Insig2 downregulation(0.56-fold) and Srebf1 upregulation were observed. Therefore, these transcriptional changes may be responsible for the significant increase in liver TG (Table 2).

Expression of the lipoprotein metabolism gene Ldlr was unchanged in the cholesterol-fed mice. However, Hdlbp, which encodes the HDL-binding protein, was increased 2.2-fold, suggesting that the HDL-binding protein facilitates removal of excess cholesterol from cells ${ }^{25}$. In contrast, expression of Scarb1, which encodes the HDL receptor, was not upregulated (1.16-fold). Cai et al. reported that SAA, which is a ligand for the scavenger receptor class B type I (SR-B1), inhibits HDL binding and selective cholesterol ester (CE) uptake and thereby influences HDL-C metabo$\mathrm{lism}^{26)}$. In agreement, Saa1 was increased 2.09-fold in the HC group. In the liver, SR-B1 plays a key role in the clearance of HDL CE and facilitates cholesterol transport from the periphery to the liver ${ }^{26)}$. Therefore, it is supposed that reverse cholesterol transport through SR-B1 was inhibited by increased SAA production.

Angiopoietin-like $4($ Angptl 4$)$ is a known inhibitor of lipoprotein lipase (LPL) activity. In this study, Angptly expression was decreased (0.50- and 0.57-fold). When LPL-dependent VLDL lipolysis is inhibited, plasma TG concentrations rise. Therefore, Angptl4 downregulation may have contributed to decreased plasma TG concentrations in the HC group. Lichtenstein et al. also suggested that Angptl 4 induced cholesterol synthesis in the liver is secondary to inhibition of LPL- and hepatic lipase-dependent hepatic cholesterol uptake ${ }^{27)}$. Although hepatic and plasma cholesterol concentrations were increased by dietary cholesterol (Table 2 and 3), suppression of cholesterol synthesis in the liver may be related to Angptl 4 downregulation. Tomita reported that Angptly suppression is involved in the pathology of non-alcoholic steatohepatitis (NASH) ${ }^{28)}$. Thus, this observation may indicate NASH development in the HC group.

Caveolin, caveolae protein 1(Cav1), which encodes a cholesterol-binding protein and plays an important role in intracellular cholesterol transport, was upregulated 1.54fold. Removal of this protein is essential for activation of endothelial nitric oxide synthase (eNOS), which is an important antiarteriosclerotic mechanism. Feron et al. demonstrated that high caveolin-1 expression decreased eNOS activation $^{29)}$. In addition, increased LDL-C significantly upregulates caveolin expression. Consistent with this, LDL-C was increased in the $\mathrm{HC}$ group (Table 3) and may have led to slight Cav1 upregulation.

\subsection{Effect of $G$. frondosa intake on the expression of lipid metabolism genes in cholesterol-loaded mice livers}

There were differences in the expression of lipid metabolic processes (GO:0006629) (Table 5). In the $\mathrm{HC}+\mathrm{G}$ group, Abcg8 expression(1.89-fold) was higher than that in the HC group. ABCG5/ABCG8 expression increases in the presence of nuclear receptor LXR agonists, leading to increased cholesterol excretion into bile ${ }^{30)}$. Our data therefore indicate that $G$. frondosa contains LXR agonists that promote cholesterol excretion.

With regard to primary bile acid synthesis, Cyp39a1 and 
Cyp $46 a 1$ were not upregulated in the $\mathrm{HC}+\mathrm{G}$ group as well as in the HC group. Substantial differences in the expression of the genes of de novo cholesterol synthesis and LDL receptors were not found between the $\mathrm{HC}+\mathrm{G}$ and $\mathrm{HC}$ groups. Although there were no significant differences in liver cholesterol, enhanced cholesterol excretion led to significant decrease in plasma cholesterol in the $\mathrm{HC}+\mathrm{G}$ group compared with the HC group. Moreover, Apob expression in the $\mathrm{HC}+\mathrm{G}$ group was similar to that in the $\mathrm{N}$ group.

Srebf1 expression is associated with fatty liver and hyperlipidemia. In these experiments, Srebf1 expression was elevated in both cholesterol-fed mice groups, but it was lower in the $\mathrm{HC}+\mathrm{G}$ group (2.74-fold) than in the HC group (3.15-fold). These results suggest decreasing hepatic TG content in the $\mathrm{HC}+\mathrm{G}$ group. Moreover, Fabp 4 expression was decreased to the level in the $\mathrm{N}$ group in the $G$. frondosa-supplemented mice, and Cav1 was upregulated in the $\mathrm{HC}$ group but not in the $\mathrm{HC}+\mathrm{G}$ group. Hence, caveolinmediated eNOS inhibition may have been limited in the HC + G group.

G. frondosa intake promoted cholesterol metabolism in a previous study ${ }^{4}$. However, similar to a study using rats by Fukushima et $a l^{2)}$, upregulation of bile acid metabolism was not observed in this study. The cholesterol-lowering effects of these mushrooms are thought to be caused by increased excretion of cholesterol and bile acid in feces ${ }^{2,4)}$, which may involve mushroom dietary fiber as discussed. $G$. frondosa contains soluble ( $0.3 \mathrm{~g} / 100 \mathrm{~g}$ boiled mushroom) and insoluble $(2.4 \mathrm{~g} / 100 \mathrm{~g}$ boiled mushroom $)$ fibers ${ }^{14)}$. These dietary fibers were corrected using insoluble cellulose powder so that the fiber content was the same in all groups. The dietary actions of soluble and insoluble fibers differ. Fukushima et al. reported plasma cholesterol-lowering effects of soluble dietary fiber ${ }^{2)}$. $\beta$-glucan is a soluble fiber found in G. frondosa and is a candidate compound for cholesterol lowering. However, the main objective of this study was to examine hepatic gene expression following dietary supplementation with $G$. frondosa. Hence, further investigation is needed to determine the active components. Fukushima et al. found that fecal cholesterol excretion was promoted by dietary $G$. frondosa ${ }^{2)}$, but the mechanism of this effect was unclear. Kubo and Nanba also showed that cholesterol and bile acid in feces of rats with $1 \%$ cholesterol (10\% lard and $2 \%$ corn oil)were increased by $G$. frondosa intake ${ }^{4)}$. As mentioned above, although a significant increase in Cyp $7 a 1$ expression was not observed, genes related to cholesterol transport and excretion into bile were slightly upregulated in the $\mathrm{HC}+\mathrm{G}$ group. Hence, these minor transcriptional changes may have cumulatively influenced plasma cholesterol content.

\subsection{Effects of cholesterol and G. frondosa intake on the expression of other genes}

As shown in Table 5, the leptin receptor gene Lepr was upregulated in the $\mathrm{HC}+\mathrm{G}$ group (1.62-fold). Therefore, we focused on the gene expression of adipocytokine signaling components (Fig. 2). As for 5'-AMP-activated protein kinase, which controls sugar and lipid metabolism and plays an important role in energy metabolism, $\mathrm{Ca}^{2+}$ -calmodulin-dependent protein kinase kinase 1 (Camkk1) was upregulated 2.27-fold in the $\mathrm{HC}+\mathrm{G}$ group. Downstream, carnitine palmitoyltransferase $(C p t 1 a)$, which is a key enzyme for $\beta$-oxidation of long-chain FAs in liver mitochondria $^{31)}$, was up-regulated 3.02-fold. This may have promoted FA oxidation, which led to decrease in liver and plasma TG. Cpt1a levels in the experimental diet groups were significantly higher than those in the $\mathrm{N}$ group, and the level in the $\mathrm{HC}+\mathrm{G}$ group was highest among the three groups. Hence, Cpt1a upregulation may moderate hepatic TG accumulation by excess cholesterol intake. This result indicates the presence of compounds in G. frondosa that induce Cpt1a upregulation. Because the mRNA level does

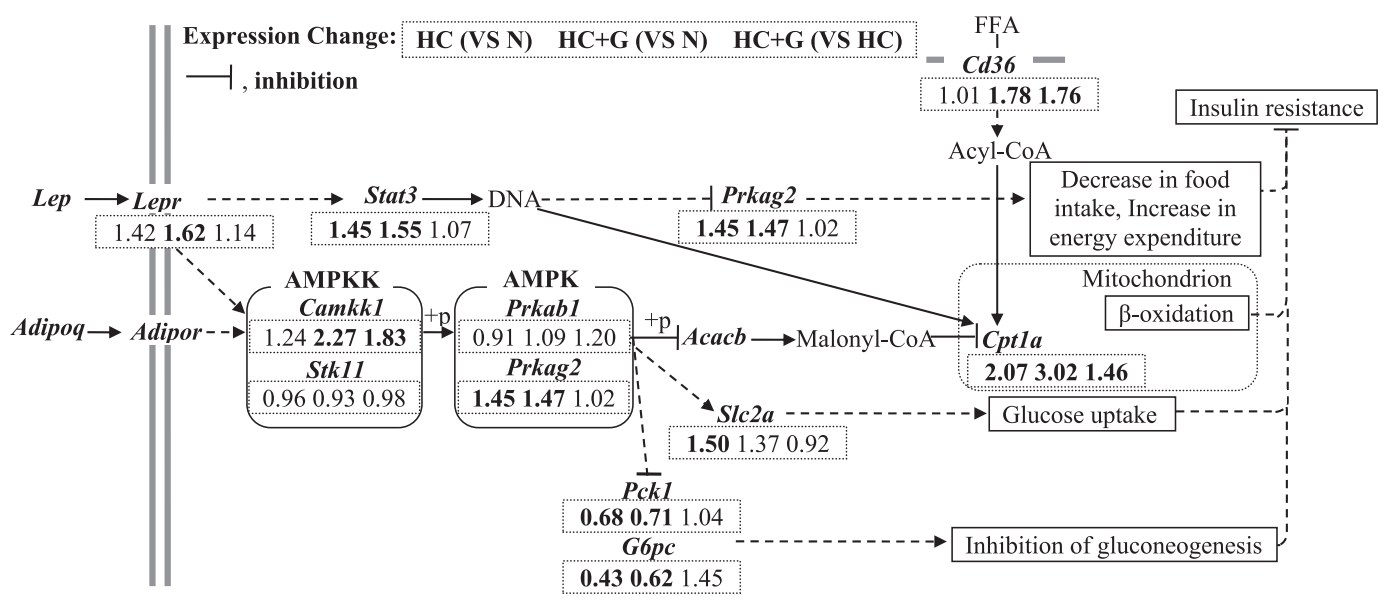

Fig. 2 Expression of Adipocytokine Signaling Genes Induced by Ingestion of Cholesterol and G. frondosa. HC, high cholesterol group; $\mathrm{H}+\mathrm{G}$, high cholesterol plus $G$. frondosa powder group. 
not necessarily accord with enzyme activity, metabolic changes are merely inferred from analyses of mRNA expression. Nonetheless, these data offer an explanation for the decline in hepatic and plasma TG concentrations in the $\mathrm{HC}+\mathrm{G}$ group compared with the HC group. Thus, $\beta$-oxidation was promoted via adipocytokine signaling following supplementation with $G$. frondosa, and the related genes (Lepr, Camkk1, Prkag2, Cpt1a) were elevated in the $\mathrm{HC}+\mathrm{G}$ group compared with the HC group. Hence, dietary intake of $G$. frondosa during high cholesterol feeding is expected to promote fat catabolism.

As suggested above, SAA inhibits cellular hepatic cholesterol reverse transport. Accordingly, Saa1 was downregulated 1.40-fold and Scarb1 was upregulated 1.53-fold in the HC + G group compared with the HC group (Table 5), suggesting that cholesterol reverse transport was promoted by dietary $G$. frondosa. A previous study indicates that elevated SAA expression is associated with cardiovascular risks, including obesity, insulin resistance, metabolic syndrome, and diabetes ${ }^{32}$. In this study, expression of SAAs (Saa1, Saa2, Saa3, and Saa4) was significantly upregulated in the HC group compared with the $\mathrm{N}$ group (1.54- to 3.56-fold), but it was suppressed in the HC + G group (1.19to 1.54 -fold). These data suggest that dietary intake of $G$. frondosa suppresses the expression of SAAs that induce arteriosclerosis.

These data indicate that dietary $G$. frondosa during cholesterol feeding promotes fat catabolism by inducing adipocytokine signaling and $\beta$-oxidation, and subsequently leads to antiatherogenic effects. Hence, dietary G. frondosa can prevent and improve the symptoms of obesity, diabetes, and arteriosclerosis induced by hypercholesterolemia.

\section{References}

1) World Health Organization. The top ten causes of death. Fact sheet, No. 310 (2011).

2) Fukushima, M.; Ohashi, T.; Fujiwara, Y.; Sonoyama, K.; Nakano, M. Cholesterol-lowering effects of maitake (Grifola frondosa) fiber, shiitake (Lentinus edodes) fiber, and enokitake (Flammulina velutipes) fiber in rats. Exp. Biol. Med. 226, 758-765 (2001).

3) Kabir, Y.; Yamaguchi, M.; Kimura, S. Effect of shiitake (Lentinus edodes) and maitake (Grifola frondosa) mushrooms on blood pressure and plasma lipids of spontaneously hypertensive rats. J. Nutr. Sci. Vitaminol. 33, 341-346 (1987).

4) Kubo, K.; Nanba, H. Anti-hyperliposis effect of maitake fruit body (Grifola frondosa). I. Biol. Pharm. Bull. 20, 781-785 (1997).

5) Mori, K.; Kobayashi, C.; Tomita, T.; Inatomi, S.; Ikeda, M. Antiatherosclerotic effect of the edible mushrooms Pleurotus eryngii (Eringi), Grifola frondosa (Maita- ke), and Hypsizygus marmoreus (Bunashimeji) in apolipoprotein E-deficient mice. Nutr. Res. 28, 335342 (2008).

6) Kaneda, T.; Tokuda, S. Effect of various mushroom preparations on cholesterol levels in rats. J. Nutr. 90, 371-376 (1966).

7) Kamiya, T.; Saito, Y.; Hashimoto, M.; Seki, H. Structure and synthesis of lentysine, a new hypocholesterolemic substance. Tetrahedron Lett. 10, 4729-4732 (1969).

8) Chibata, I.; Okumura, K.; Takeyama, S.; Kotera, K. Lentinacin: a new hypocholesterolemic substance in Lentinus edodes. Experientia 25, 1237-1238(1969).

9) Saito, M.; Yasumoto, T.; Kaneda, T. Quantitative analyses of eritadenine in "shii-ta-ke" mushroom and other edible fungi. Eiyo To Shokuryo 28, 503-505 (1975).

10) Sato, M.; Tokuji, Y.; Yoneyama, S.; Fujii-Akiyama, K.; Kinoshita, M.; Ohnishi, M. Profiling of hepatic gene expression of mice fed with edible Japanese mushrooms by DNA microarray analysis: comparison among Pleurotus ostreatus, Grifola frondosa, and Hypsizigus marmoreus. J. Agric. Food Chem. 59, 10723-10731 (2011).

11) Takayanagi, K.; Morimoto, S.; Shirakura, Y.; Mukai, K.; Sugiyama, T.; Tokuji, Y.; Ohnishi, M. Mechanism of visceral fat reduction in Tsumura Suzuki obese, diabetes (TSOD) mice orally administered $\beta$-cryptoxanthin from Satsuma mandarin oranges (Citrus unshiu Marc). J. Agric. Food Chem. 59, 12342-12351(2011).

12) Tokuji, Y.; Akiyama, K.; Yunoki, K.; Kinoshita, M.; Sasaki, K.; Kobayashi, H.; Wada, M.; Ohnishi, M. Screening for beneficial effects of oral intake of sweet corn by DNA microarray analysis. J. Food Sci. 74, H197-203 (2009).

13) Yoneyama, S.; Gisusi, S.; Harada, A.; Mori, M. Screening of new maitake (Grifola frondosa) variety for using cultivation on larch (Larix leptolepis) wood as the substrate. J. Hokkaido For. Prod. Res. Inst. 20, 21-26 (2006).

14) Resources Council, Science and Technology Agency, Japan. Standard Tables of Food Composition in Japan. $5^{\text {th }}$ revised ed. Dai-ichi shuppan., Tokyo, pp. 172$173(2001)$.

15) Danno, H.; Jincho, Y.; Budiyanto, S.; Furukawa, Y.; Kimura, S. A simple enzymatic quantitative analysis of triglycerides in tissues. J. Nutr. Sci. Vitaminol. 38, 517-521 (1992).

16) Gertler, M. M.; Garn, S. M.; Lerman, J. The interrelationships of serum cholesterol, cholesterol esters and phospholipids in health and in coronary artery disease. Circulation 2, 205-214(1950).

17) Hui, D. Y.; Howles, P. N. Molecular mechanisms of cholesterol absorption and transport in the intestine. $S e$ min. Cell Dev. Biol. 16, 183-192 (2005).

18) Ikeda, I.; Kudo, M.; Hamada, T.; Nagao, K.; Oshiro, Y.; 
Kato, M.; Sugawara, T.; Yamahira, T.; Ito, H.; Tamaru, S.; Sato, M.; Imaizumi, K.; Nagaoka, S.; Yanagita, T. Dietary soy protein isolate and its undigested high molecular fraction upregulate hepatic ATP-binding cassette transporter G5 and ATP-binding cassette transporter G8 mRNA and increase biliary secretion of cholesterol in rats. J. Nutr. Sci. Vitaminol. 55, 252256 (2009).

19) Berge, K. E.; Tian, H.; Graf, G. A.; Yu, L.; Grishin, N. V.; Schultz, J.; Kwiterovich, P.; Shan, B.; Barnes, R.; Hobbs, H. H. Accumulation of dietary cholesterol in sitosterolemia caused by mutations in adjacent ABC transporters. Science 290, 1771-1775 (2000).

20) Repa, J. J.; Berge, K. E.; Pomajzl, C.; Richardson, J. A.; Hobbs, H.; Mangelsdorf, D. J. Regulation of ATP-binding cassette sterol transporters ABCG5 and ABCG8 by the liver X receptors alpha and beta. J. Biol. Chem. 277, 18793-18800(2002).

21) Cabré, A.; Lázaro, I.; Girona, J.; Manzanares, J. M.; Marimón, F.; Plana, N.; Heras, M.; Masana, L. Fatty acid binding protein 4 is increased in metabolic syndrome and with thiazolidinedione treatment in diabetic patients. Atherosclerosis 195, e150-158(2007).

22) Westerbacka, J.; Kolak, M.; Kiviluoto, T.; Arkkila, P.; Sirén, J.; Hamsten, A.; Fisher, R. M.; Yki-Järvinen, H. Genes involved in fatty acid partitioning and binding, lipolysis, monocyte/macrophage recruitment, and inflammation are overexpressed in the human fatty liver of insulin-resistant subjects. Diabetes 56, 2759-2765 (2007).

23) Fu, Y.; Luo, L.; Luo, N.; Garvey, W. T. Lipid metabolism mediated by adipocyte lipid binding protein (ALBP/ aP2) gene expression in human THP-1 macrophages. Atherosclerosis 188, 102-111(2006).

24) Yabe, D.; Komuro, R.; Liang, G.; Goldstein, J. L.; Brown, M. S. Liver-specific mRNA for Insig-2 downregulated by insulin: implications for fatty acid synthesis. Proc. Natl. Acad. Sci. U. S. A. 100, 3155-3160 (2003).

25) McKnight, G. L.; Reasoner, J.; Gilbert, T.; Sundquist, K. O.; Hokland, B.; McKernan, P. A.; Champagne, J.;
Johnson, C. J.; Bailey, M. C.; Holly, R.; O’Hara, P. J.; Oram, J. F. Cloning and expression of a cellular high density lipoprotein-binding protein that is upregulated by cholesterol loading of cells. J. Biol. Chem. 267, 12131-12141 (1992).

26) Cai, L.; de Beer, M. C.; de Beer, F. C.; van der Westhuyzen, D. R. Serum amyloid A is a ligand for scavenger receptor class B type I and inhibits high density lipoprotein binding and selective lipid uptake. J. Biol. Chem. 280, 2954-2961 (2005).

27) Lichtenstein, L.; Berbée, J. F.; van Dijk, S. J.; van Dijk, K. W.; Bensadoun, A.; Kema, I. P.; Voshol, P. J.; Müller, M.; Rensen, P. C.; Kersten, S. Angptl4 upregulates cholesterol synthesis in liver via inhibition of LPL- and HL-dependent hepatic cholesterol uptake. Arterioscler. Thromb. Vasc. Biol. 27, 2420-2427 (2007).

28) Tomita, K. 172. Involvement of Angpt14 in the pathological mechanisms of steatosis and steatohepatitis: The development of a new therapeutic strategy. Research Reports of Uehara Memorial Foundation Research Report. 23. (2009).

29) Feron, O.; Dessy, C.; Desager, J. P.; Balligand, J. L. Hydroxy-methylglutaryl-coenzyme A reductase inhibition promotes endothelial nitric oxide synthase activation through a decrease in caveolin abundance. Circulation 103, 113-118(2001).

30) Yu, L.; York, J.; von Bergmann, K.; Lutjohann, D.; Cohen, J. C.; Hobbs, H. H. Stimulation of cholesterol excretion by the liver $\mathrm{X}$ receptor agonist requires ATPbinding cassette transporters G5 and G8. J. Biol. Chem. 278, 15565-15570(2003).

31) McGarry, J. D.; Brown, N. F. The mitochondrial carnitine palmitoyltransferase system. From concept to molecular analysis. Eur. J. Biochem. 244, 1-14 (1997).

32) Chait, A.; Han, C. Y.; Oram, J. F.; Heinecke, J. W. Thematic review series: The immune system and atherogenesis. Lipoprotein-associated inflammatory proteins: markers or mediators of cardiovascular disease? $J$. Lipid Res. 46, 389-403(2005). 